\title{
General Psychiatry Children emotional and behavioural problems and its association with maternal depression in Jimma town, southwest Ethiopia
}

\author{
Arefayne Alenko (D) ${ }^{1}$ Shimelis Girma, ${ }^{1}$ Mubarek Abera, ${ }^{1}$ Abdulhalik Workicho ${ }^{2}$
}

To cite: Alenko A, Girma S, Abera $\mathrm{M}$, et al. Children emotional and behavioural problems and its association with maternal depression in Jimma town, southwest Ethiopia. General Psychiatry 2020;33:e100211. doi:10.1136/ gpsych-2020-100211

- Additional material is published online only. To view please visit the journal online (http://dx.doi.org/10.1136/ gpsych-2020-100211).

Received 18 February 2020 Revised 01 June 2020 Accepted 03 June 2020

Check for updates

(C) Author(s) (or their employer(s)) 2020. Re-use permitted under CC BY-NC. No commercial re-use. See rights and permissions. Published by BMJ.

${ }^{1}$ Psychiatry, Jimma University College of Public Health and Medical Sciences, Jimma,

Ethiopia

${ }^{2}$ Epidemiology, Jimma University College of Public Health and Medical Sciences, Jimma, Ethiopia

Correspondence to Mr Arefayne Alenko; arefeaynealenko@gmail.com

\section{ABSTRACT}

Background In sub-Saharan countries, one in five children and one in three women experiences emotional and behavioural problems (EBPs) and depression, respectively. While various factors were reported to affect the mental health of children, little is known about the impact of maternal depression on the offspring. Moreover, the magnitude of children's EBPs is barely known in Ethiopia.

Aim To determine the magnitude of child EBPs and its association with maternal depression in Jimma town, southwest Ethiopia.

Methods A quantitative cross-sectional study was conducted among 734 mother-child pairs in Jimma town from January to June, 2019. EBP was assessed by using the parent version of Strengths and Difficulties Questionnaire (SDQ) with cut-off score of $\geq 14$. Maternal depression was assessed using Patient Health Questionnaire- 9 with a cut-off score of $\geq 10$. Data were entered into Epidata V.3.1 and exported to SPSS V.24 for analysis. Multivariable logistic regression was fitted to identify the strength of association between exposure and outcome variables.

Results Of the 734 participants, $146(19.9 \%, 95 \% \mathrm{Cl}$ : $16.9 \%$ to $22.9 \%$ ) met EBP criteria based on parent version of SDQ. Maternal depression had significant association with child EBP (adjusted $\mathrm{OR}=2.38,95 \% \mathrm{Cl}: 1.55$ to 3.66 ). In addition, children aged 7-10 years, family size categories of $\leq 3$ and 4-6, maternal intimate partner violence and maternal khat use had significant association with child EBP.

\section{Conclusions and recommendations A significant} number of children suffer from EBP in Jimma town. Maternal depression is found to be a predictor of children's EBPs. Thus, there is a need to design and implement an integrated maternal and child mental health programme. The maternal and child health section at the national level should integrate and cascade routine maternal and child mental health screening and intervention modalities down to the family healthcare system.

\section{INTRODUCTION}

Emotional and behavioural problems (EBPs) are the most commonly occurring mental illnesses in preschool and school age children. ${ }^{12}$ EBPs in children can be categorised as 'internalising' (emotional disorders such as depression and anxiety) and 'externalising' (aggressive and disruptive behaviours in attention-deficit/hyperactivity disorder (ADHD), oppositional defiant disorder and conduct disorder). Children with internalising problems tend to deal with emotional conflict internally, thus causing more distress to the child than to the family, as opposed to children with externalising problems. ${ }^{2}$

Challenging behaviours and difficult emotions in children are more likely to be an EBP rather than a disorder during the first 2 years of life. ${ }^{3}$ EBPs are more pronounced when children start school or just before starting school (preschool age). This is due to the effect of EBPs on children's academic performance and peer relation. At this time, EBPs become a common concern for parents, surrogates and teachers. ${ }^{4}$ EBPs of children have been linked to failure to complete schooling, poor school performance and poor relation with peers. It also results in family breakdown/separation, divorce and long term unemployment as a result of keeping children at home. ${ }^{2}$

It is estimated that one in five children experiences EBP in a given year, and an estimated US $\$ 247$ billion is spent each year on management of mental disorders in children. ${ }^{5}$ In the USA, $9.4 \%$ (6.1 million) of children aged 2-17 years have $\mathrm{ADHD}^{6}$ and $7.4 \%$ of children aged 3-17 years ( 4.5 million) have a diagnosed behavioural problem. Regarding emotional problems, $7.1 \%$ (approximately 4.4 million) and $3.2 \%$ (approximately 1.9 million) of children aged 3-17 years have been diagnosed with anxiety and depression, respectively in the USA. The comorbidity of emotional (depression and anxiety) and behavioural problems are also most common in children in the USA. In the USA, $73.8 \%$ aged $3-17$ years with depression also have anxiety and 


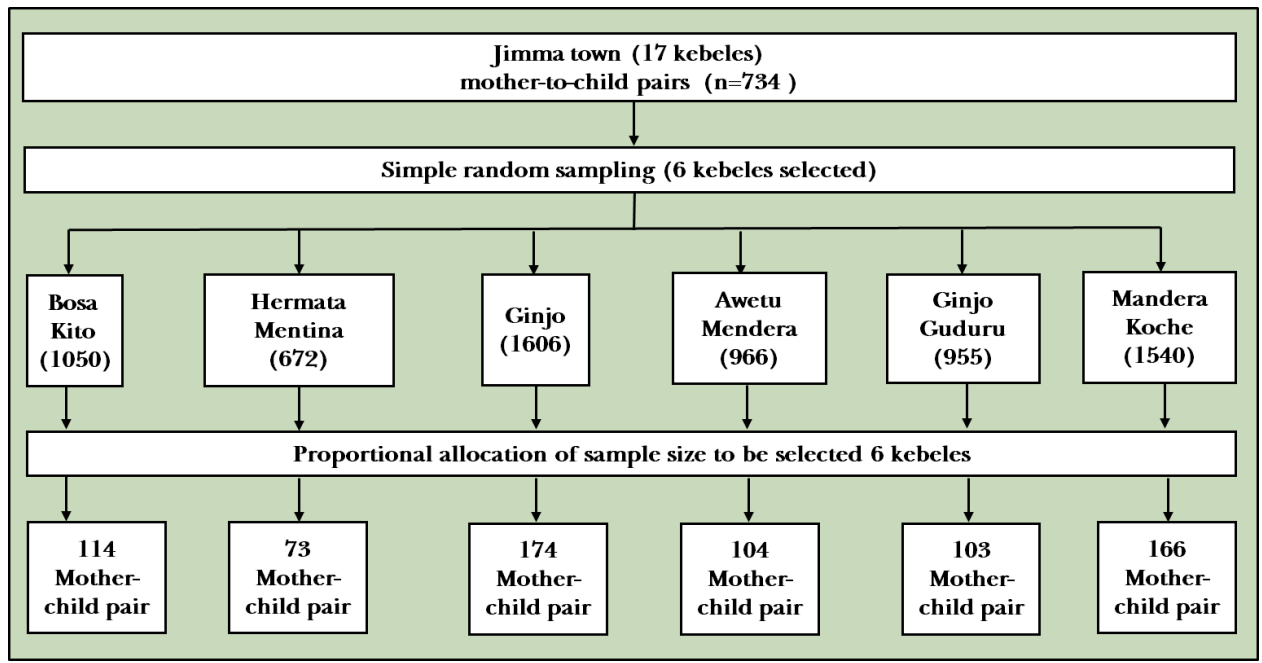

Figure 1 Figure 1Diagrammatic presentation of sampling procedure of mother-child pair in Jimma town, southwest Ethiopia, 2019(n=734).

$47.2 \%$ have behavioural problems. ${ }^{7}$ In Lithuania, $14.0 \%$ aged 7-10 years had mental disorders according to the study conducted from 2004 to 2007. In this study, higher prevalence of conduct $(7.1 \%)$ and anxiety disorders $(5.9 \%)$ than ADHD $(2.9 \%)$, was reported. ${ }^{8}$ In Nepal, the prevalence of EBPs in school children was 12.9\%-17.03\%. The clinical prevalence of anxiety disorders was $18.8 \%-$ $24.4 \%$ and ADHD was $10 \%-11.7 \%$ in different clinical samples of children and adolescents. ${ }^{9}$ Higher prevalence of behavioural problems (23.1\%) among school children aged 6-12 years was reported in Nigeria in 2006. Among children with behavioural problems, $68.2 \%$ had conduct problems. ${ }^{10}$ Clinical and borderline EBP among Kenyan children aged $6-11$ years in 2018 was $17 \%$ and $27 \%$, respectively. ${ }^{11}$ In sub-Saharan countries including Ethiopia, 1 in 5 children (19.8\%) had significant difficulties and 1 in $10(9.5 \%)$ had a specific mental disorder, according to the report of a systemic review conducted in 2012. ${ }^{12}$ The prevalence of mental health problems in Jimma town in 1995 was, $29.0 \%$ among boys and 24.8\% among girls, aged 6-11 years. ${ }^{13}$ Maternal depression markedly increases a child's susceptibility to social problems, including social isolation, poor emotion regulation and lack of empathy towards other children.

Maternal depression has received a great deal of attention in terms of its association with child EBPs in different contexts. Children of depressed mothers have been shown to be at increased risk for conduct problems compared with children of non-depressed mothers. ${ }^{14}$ Maternal depression markedly increases a child's susceptibility to social problems, including social isolation, poor emotion regulation and lack of empathy towards other children. ${ }^{15}$ In addition to maternal depression, individual characteristics of the child (gender, poor general health and stressful life experiences) have roles in the development of EBPs. ${ }^{816}$ Family background characteristics like social disadvantage, marital instability, single parenthood, unfavourable family climate and disciplining difficulties can also contribute to the development of EBPs in children. ${ }^{1617}$

Since up to $32.3 \%$ of women in sub-Saharan countries suffer from depression, ${ }^{18}$ its association with children's EBPs is not well explored in this region including Ethiopia. Therefore, this study aimed to assess the magnitude of child EBPs, and its association with maternal depression in southwest Ethiopia.

\section{METHODS AND MATERIALS \\ Study area and period}

Jimma town, the site for the current study, is located in the Jimma Zone of Oromia Regional state, which is $352 \mathrm{~km}$ southeast from Addis Ababa, capital city of Ethiopia. Based on figures from the Central Statistical Agency in 2005, this town has an estimated total population of 159 009, of whom 80897 were males and 78112 were females. The study was conducted from 1 January to 30 June, 2019.

\section{Study design and population}

Community based cross-sectional study design was conducted. All mothers of Jimma town who have children aged 3-10years (mother-child pair) were the target population for this study. Among mothers who have more than one child aged from 3 years to 10 years, the oldest child was included in the study. Among mothers who gave birth 4 weeks prior to the study period, mother and child with acute illness and twins were excluded from the study.

\section{Sample size estimation}

The sample size required for this study was calculated by using a single population proportion formula with $95 \%$ of confidence level, $5 \%$ margin of error and considering prevalence of EBPs 27\% (proportion=0.27) from a study conducted in Kenya. ${ }^{11}$ Given the above parameters, the minimum sample size needed for this study was estimated to be 303. Given the multistage nature of the sampling 


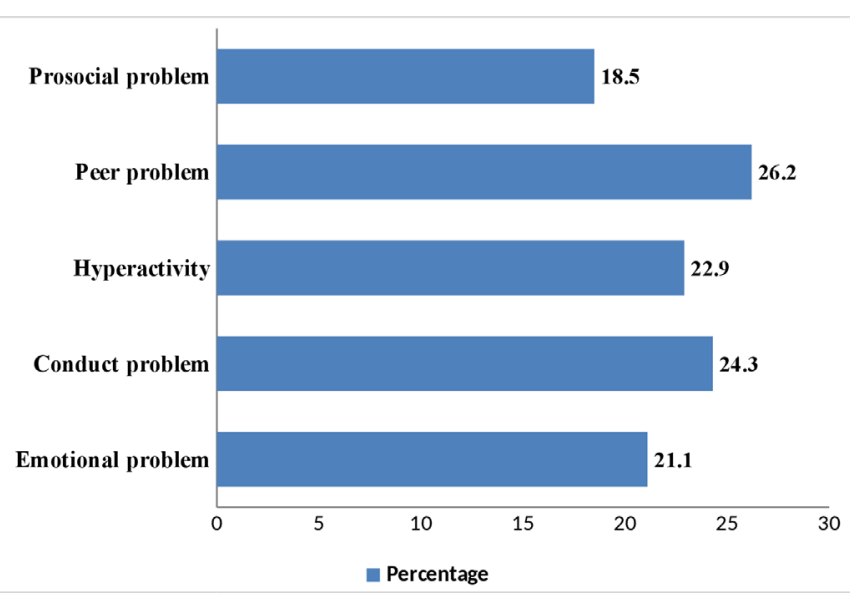

Figure 2 Prevalence of specific types of emotional and behavioural problems in Jimma town, southwest Ethiopia, 2019 (n=734).

method, we used a design effect of 2 and considered $10 \%$ non-response rate. Thus, the final sample size became 666.6. Therefore, 667 mother-child pairs were needed in this study. Since this research was part of a mega research project which included a total of 734 mother-child pairs, we had data for an additional 67 participants which we included in the analysis. So, a total of 734 mother-child pairs participated in the study.

\section{Sampling technique}

A multistage sampling technique was employed. First, from 17 kebeles in the town, we randomly selected six kebeles/villages, from where we selected our study participants. Then we retrieved a list of households with a mother-child (3-10 years of age) pair in the selected kebeles. The list, which was used as a sampling frame, was obtained from health posts of selected kebeles. The sample was allocated proportional to the size per respective kebeles using a simple random sampling method (figure 1).

\section{Methods of data collection and tools}

Data collection was done through house to house visit. Data were collected from mothers of children by using structured interviewer administered questionnaires. An English version questionnaire which was translated to the local language, Amharic and afan Oromo, was used to collect data.

\section{Main outcome variable}

Child EBP was assessed by using parent version of Strengths and Difficulties Questionnaire $(\mathrm{SDQ}) \cdot{ }^{19}$ It is a well-validated tool, translated into 60 languages of the world including those of African countries like Chichewa (Malawian local language).$^{20}$ The SDQ has 25 items rated on a three-point Likert Scale: not true $=0$, somewhat true $=1$ and certainly true $=2$. It has five subscales: emotional problems, conduct problems, hyperactivity/inattention, peer relationship problems and pro-social behaviour. The first four subscales refer to problem behaviours while the fifth (pro-social behaviour) refers to positive behaviour. Each subscale has five items. The total difficulties score is the sum of scores from the first four subscales, except the pro-social subscale, and it ranges from 0 to 40 . The scale has adequate internal consistency (Cronbach's alpha, $0.78-0.82$ ) and predictive validity ${ }^{19}$ Mothers' report of their child's emotional and behavioural difficulties was the primary outcome variable of the study. The newer band categorisation of the SDQ total difficulties score was used $(0-13=$ ='close to average'; $14-16=$ 'slightly raised'; $17-19=$ ='high'; $>19=$ ='very high'). The sum of the last three groups (slightly raised/high/very high) is considered as having problematic behaviour. ${ }^{19}$ Therefore, in this study the total SDQ score of $\geq 14$ is considered as having EBP.

\section{Main exposure}

Maternal depression was assessed using Patient Health Questionnaire-9 (PHQ-9). PHQ-9 is a commonly used tool to assess maternal depression. PHQ-9 score $\geq 10$ had a sensitivity of $88 \%$ and a specificity of $88 \%$ for major depression. $^{21} 22$ Afan Oromo version of PHQ-9 is validated in Ethiopia with sensitivity of $80.8 \%$ and specificity of $79.5 \% .^{23}$

\section{Covariates}

Maternal intimate partner violence (IPV) was assessed using hurt/insult/threaten/scream (HITS) ${ }^{24}$ HITS is validated and the most commonly used tool to assess IPV among women with cut-off score of $\geq 10{ }^{24} 25$ The current substance use of mothers was assessed by using 'yes/ no' questions. The substances assessed in this study are alcohol (the use of any alcohol containing drinks), 'khat' (local stimulant plant, cigarette smoking and cannabis use). Sociodemographic data of mothers (age, marital status, educational status and occupation) and children (age, sex and birth order) was collected by using a checklist. In addition, family characteristics of households of mother-child pair (family size, number of children $<5$ years old and number of children $<18$ years old) were assessed.

Training was given to the data collectors and supervisors for 2 days. The prepared questionnaire was checked thoroughly for its completeness, objective and common understanding before it was distributed to data collectors. The interviewers (data collectors) were 15 registered clinical nurses working in kebele health posts. The supervisors were two Masters of Science mental health professionals. Any errors, ambiguity, incompleteness, or other encountered problems were addressed immediately after supervisors received filled questionnaires from each data collector.

\section{Data management and statistical analysis}

Data were checked for completeness, coded and entered into Epiata V.3.1 and exported to SPSS V.24.0 for analysis. Exploratory analysis was performed first to identify outliers, to assess distribution of the data and to check if assumptions for multivariable regression analysis are 
Table 1 Sociodemographic characteristics of study participants in Jimma town, southwest Ethiopia, 2019 $(n=734)$

\begin{tabular}{|c|c|c|c|}
\hline Variables & Category & Frequency & Percentage \\
\hline \multirow[t]{2}{*}{ Sex } & Male & 372 & 50.7 \\
\hline & Female & 362 & 49.3 \\
\hline \multirow[t]{2}{*}{ Child age (years) } & $3-6$ & 525 & 71.5 \\
\hline & $7-10$ & 209 & 28.5 \\
\hline \multirow[t]{4}{*}{ Birth order } & First & 377 & 51.4 \\
\hline & Second & 190 & 25.9 \\
\hline & Third & 102 & 13.9 \\
\hline & $\begin{array}{l}\text { Fourth and } \\
\text { above }\end{array}$ & 65 & 8.0 \\
\hline \multirow[t]{3}{*}{ Maternal age (years) } & $20-29$ & 355 & 48.4 \\
\hline & $30-39$ & 333 & 45.4 \\
\hline & $40-49$ & 46 & 6.2 \\
\hline \multirow[t]{5}{*}{ Marital status } & Married & 435 & 59.3 \\
\hline & Single & 58 & 7.9 \\
\hline & Divorced & 85 & 11.6 \\
\hline & Separated & 97 & 13.2 \\
\hline & Widowed & 59 & 8.0 \\
\hline \multirow[t]{4}{*}{ Educational status } & $\begin{array}{l}\text { No formal } \\
\text { education }\end{array}$ & 147 & 20 \\
\hline & $\begin{array}{l}\text { Primary } \\
\text { education }\end{array}$ & 310 & 42.2 \\
\hline & $\begin{array}{l}\text { Secondary } \\
\text { education }\end{array}$ & 194 & 26.4 \\
\hline & $\begin{array}{l}\text { Higher } \\
\text { education }\end{array}$ & 83 & 11.3 \\
\hline \multirow[t]{4}{*}{ Occupation } & House wife & 527 & 71.8 \\
\hline & $\begin{array}{l}\text { Gov't } \\
\text { employee }\end{array}$ & 98 & 13.4 \\
\hline & Merchant & 70 & 9.5 \\
\hline & Daily labour & 39 & 5.3 \\
\hline
\end{tabular}

Gov't, government.

met. Then, descriptive analysis was done to generate summary values of the outcome and explanatory variables. Frequency and percentages were calculated for categorical variables while mean and SD were calculated for continuous variables. Variables for multivariable regression analysis were selected on the basis of their association with the outcome variable at $\mathrm{p}<0.25$, presence of biologically plausible relationship with the outcome and consultation of previous literature. Adjusted OR (AOR) with $95 \%$ CI was estimated to determine the strength of association between EBPs and explanatory variables. Statistical significance was set at $\mathrm{p}<0.05$.

\section{RESULTS}

Sociodemographic characteristics of study participants

The mean (SD) age of children was found to be 5.35 (2.04) years with minimum and maximum ages of 3 and 10 years, respectively. More than half of the children
Table 2 Family characteristics, maternal depression and substance use among study participants in Jimma town, southwest Ethiopia, $2019(n=734)$

\begin{tabular}{|c|c|c|c|}
\hline Variables & Category & Frequency & Percentage \\
\hline \multirow[t]{2}{*}{ Maternal depression } & Yes & 174 & 23.7 \\
\hline & No & 560 & 76.3 \\
\hline \multirow[t]{3}{*}{ Family size } & $\leq 3$ & 156 & 21.3 \\
\hline & $4-6$ & 491 & 66.9 \\
\hline & $\geq 7$ & 87 & 11.9 \\
\hline \multirow{4}{*}{$\begin{array}{l}\text { Number of children }<5 \\
\text { years }\end{array}$} & 0 & 97 & 13.2 \\
\hline & 1 & 464 & 63.2 \\
\hline & 2 & 151 & 20.6 \\
\hline & 3 & 22 & 3.0 \\
\hline \multirow{5}{*}{$\begin{array}{l}\text { Number of children }<18 \\
\text { years }\end{array}$} & 0 & 23 & 3.1 \\
\hline & 1 & 206 & 28.1 \\
\hline & 2 & 259 & 35.3 \\
\hline & 3 & 132 & 18.0 \\
\hline & $\geq 4$ & 114 & 15.5 \\
\hline \multirow{2}{*}{$\begin{array}{l}\text { Maternal intimate } \\
\text { partner violence }\end{array}$} & Yes & 118 & 16.1 \\
\hline & No & 616 & 83.9 \\
\hline \multirow[t]{2}{*}{ Alcohol use } & Yes & 56 & 7.6 \\
\hline & No & 678 & 92.4 \\
\hline \multirow[t]{2}{*}{ Khat use } & Yes & 224 & 30.5 \\
\hline & No & 510 & 69.5 \\
\hline \multirow[t]{2}{*}{ Cigarette smoking } & Yes & 35 & 4.8 \\
\hline & No & 699 & 95.2 \\
\hline \multirow[t]{2}{*}{ Cannabis use } & Yes & 10 & 1.4 \\
\hline & No & 724 & 98.6 \\
\hline
\end{tabular}

were boys, $372(50.7 \%)$ and aged 3-6years, $525(71.5 \%)$. Regarding birth order, majorities were first, 377 (51.4). The mean (SD) age of mothers was found to be 29.88 (5.41) years with minimum and maximum ages of 20 and 48 years, respectively. Details of sociodemographic characteristics are presented in table 1.

\section{Maternal depression and related family characteristics}

The majority of households, 491 (66.9\%) have a family size of 4-6. Regarding the number of children, majority of households have one child under 5 years and two children under 18 years, $464(63.2 \%)$ and $256(35.3 \%)$, respectively. One hundred and eighteen $(16.1 \%)$ mothers experienced IPV. Nearly one-fourth (23.7\%) of mothers' have had depression (screen positive) based on PHQ-9. Fifty-six $(7.6 \%)$ mothers use alcohol containing drinks, $224(30.5 \%)$ chew khat, $15(2.0 \%)$ smoke cigarettes and $10(1.4 \%)$ use cannabis (table 2$)$.

\section{Prevalence of EBPs in children}

Based on SDQ, the prevalence of EBP was found to be 146 (19.9\%) (95\% CI: 16.9 - 22.9\%). Among children with EBPs; $88(12.0 \%)$ were 'slightly raised', $34(4.6 \%)$ were 'high' and $25(3.4 \%)$ were 'very high' based on four band SDQ severity 
Table 3 Multivariate logistic regression analysis of factors associated with children EBPs in Jimma town, southwest Ethiopia $(n=734)$

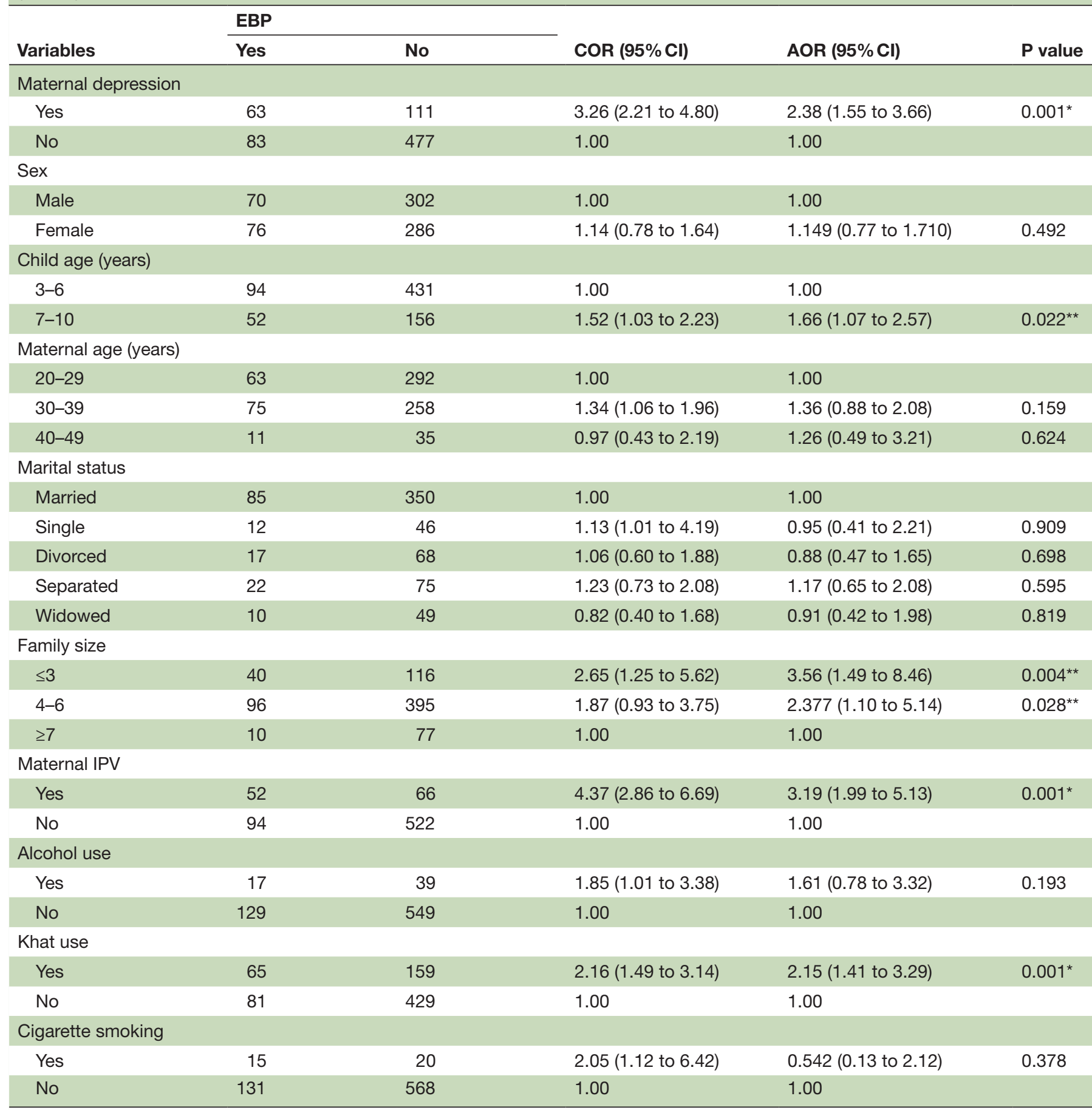

${ }^{*} \mathrm{P}<0.001,{ }^{* *} \mathrm{p}<0.05$.

AOR, adjusted OR; COR, crude OR; EBP, emotional and behavioural problem; IPV, intimate partner violence.

categorisation. The most prevalent type of EBPs was peer problem (26.2\%) and conduct problem (24.3\%) (figure 2).

Association between child EBPs, and maternal depression In multivariable logistic regression, a child EBP is associated with maternal depression with $\mathrm{AOR}=2.38,95 \% \mathrm{CI}: 1.55$ to 3.66 and p values $<0.001$. The other factors which are independently associated with EBP are: children aged 7-10years (AOR=1.66, 95\% CI: 1.07 to 2.57 ), family sizes of $\leq 3$ (AOR=3.56, 95\% CI:
1.49 to 8.46$)$ and $4-6(\mathrm{AOR}=2.37,95 \% \mathrm{CI}: 1.10$ to 5.14$)$, maternal IPV (AOR=3.19, 95\% CI: 1.99 to 5.13) and maternal khat use (AOR=2.15, 95\%CI: 1.41 to 3.29$)$ had shown significant association with child EBP (table 3).

\section{DISCUSSION}

Main findings

The findings of this study revealed that a significant proportion of children are currently experiencing EBPs 
in Jimma town. The prevalence of EBP in general is found to be $146(19.9 \%)$, (95\% CI: $16.9-22.9 \%)$. The finding of this study is in line with the Centers for Disease Control and Prevention 2019 report in which one in five children experiences EBP in a given year. ${ }^{5}$ This study is also consistent with a systematic review conducted in subSaharan countries. In sub-Saharan countries, one in five children $(19.8 \%)$ had significant difficulties. ${ }^{12}$ The most recent study conducted in Kenya reported that $17 \%$ of children have clinical EBP. ${ }^{11}$ The finding of the Kenyan study is also consistent with our finding. Contrary to the current study, the lower prevalence of EBP was reported in Lithuania $(14.05 \%)^{8}$ and Nepal $(12.9 \%-17.03 \%) .^{9}$ The difference might be due to different countries' socioeconomic status, the age of children involved in the study (7-10years) and year of study such as study conducted in Lithuania (2004-2007). The higher prevalence of EBP is reported in Nigeria $(23.1 \%)^{10}$ and Jimma town $(29.0 \%$ among boys and $24.8 \%$ among girls). ${ }^{13}$ The difference might be due to the age of children involved in the studies (6-12 years) and the difference in study year $(2006,1995)$ in the previous studies.

The odds of developing EBPs among children of mothers with depression were 2.4 times higher compared with children of mothers without depression $(\mathrm{AOR}=2.38$, $95 \%$ CI: 1.55 to 3.66$)$. The finding agrees with the studies conducted by Beck ${ }^{14}$ and Pratt and his colleagues. ${ }^{15}$ Beck reported that the risk of conduct problem is higher among children of depressed mothers compared with children of non-depressed mothers. ${ }^{14}$ According to the report of Pratt and his colleagues, ${ }^{15}$ maternal depression markedly increases a child's susceptibility to social and emotional problems, and lack of empathy for other children. This might be due to the fact that depressed mothers are insensitive to their children and could be more likely to choose harsh parenting skills. ${ }^{26}$ Maternal depression can result in compromised nutrition and diet during early development of children leading to impaired mental health. This is explained by the association between maternal depression and stunted growth between 6-12 months of age in Bangladesh. ${ }^{27}$ Therefore, child growth, particularly in the first years of life characterised by rapid brain development, can have implications for child emotional and behavioural development. In general, the underlying mechanisms of maternal depression and early childhood mental illness could be seen in terms of biological, psychological and social factors, even though there is scarcity of adequate knowledge in this regard. ${ }^{28}$ In sub-Saharan countries, poverty and social insecurity increase the risk of maternal depression. Maternal depression in turn results in impaired motherchild attachment. Poor mother-child attachment can compromise child emotional and behavioural development ${ }^{2930}$ and compromise patience necessary for quality interaction and relationships with their children. ${ }^{31}$ In addition, mothers with depression have higher expressed emotion towards their children than non-depressed mothers, which could contribute to the development of child EBPs. ${ }^{32}$ In general, maternal depression could negatively impact a wide range of adverse child outcomes such as mental illness, poor physical health and poor social and academic functioning.

The odds of developing EBP among children aged 7-10years is 1.5 times higher compared with children aged 3-6 years. This might be due to a higher level of stress and discomfort originating from academics and school environment which are challenging for young children, negative effects of insufficiency and adverse childhood experiences. ${ }^{33}$ The odds of having EBP in children within family sizes of $\leq 3$ and 4-6 were 3.5 times and 2.3 times higher, respectively than children within family size of $>7$. This finding agrees with the finding of a Norwegian mother and child cohort study. In the Norwegian study, children of large family size are less likely to develop mental problems compared with children of small family size. ${ }^{34}$ This might be due to the fact that in large families, there is decreased home activity burden due to responsibility sharing, caring for each other, support system within family and lack of loneliness. Moreover, children in a larger family might have more care and security than those in a smaller family. Children of mothers who experienced IPV were 3.2 times more likely to develop EBP than children of mothers who did not experience IPV. Maternal IPV can cause family instability and unfavourable family climate. Such circumstances result in psychological distress in children and they finally end up with an emotional problem/disorder. ${ }^{16}{ }^{17}$ The odds of developing EBPs among children of mothers who use/chew khat were two times higher compared with children of mothers who do not use khat. To the knowledge of the researchers, there is no evidence regarding the direct relation/association between child mental illness and maternal khat use. Further research might be needed to explain this association.

\section{Limitations}

The study has several strengths. First, we included an adequate sample from a well-defined catchment area. Second, we used validated instruments/tool to assess child EBPs, and maternal depression. Third, we included households with mother-child pairs. A limitation of the study is that since the study primarily focused on maternal related factors of children EBPs, we did not capture child specific factors such as child abuse and maltreatment that could have occurred and affected the outcome. Another limitation is due to the crosssectional nature of the study, the association between different factors and EBP does not imply cause-effect relationship.

\section{Implications}

To improve the overall health and well-being of children, it is important to target and ensure good mental health of their mothers/caregivers. Children of mothers with mental illness also need special attention to protect them from developing EBPs. In general, the mental health of 
mothers and their offspring is inseparable and demands integrated care. Integration of mental healthcare into the family healthcare system organised by the national maternal and child health unit is paramount to improve the overall maternal and child health and well-being.

\section{CONCLUSION}

In the current study, the prevalence of children EBP is high. Maternal depression is found to be an independent predictor of child EBP. Routine screening and counselling for mothers/caregivers of children is indicated. Thus, there is a need to design, integrate and implement routine mental healthcare into the family healthcare system to tackle both maternal and child mental health problems simultaneously. We recommend further longitudinal research in order to identify cause-effect relationship between child EBP and associated factors.

Acknowledgements The authors acknowledge Jimma University Institute of Health for funding the study. Jimma town health department and kebeles, study participants and data collectors are also highly acknowledged.

Contributors AA collected and analysed the data, reviewed the literature and wrote the manuscript. SG was involved in data collection and data analysis. MA and AW were involved in data analysis, writing the manuscript and editing the manuscript. All the coauthors checked the manuscript for language, analysis of data and interpretation.

Funding This research work is funded by Jimma University Institute of Health (Ref No. IHRPGD 594/2019).

Competing interests None declared.

Patient consent for publication Not required.

Ethics approval Ethical approval was obtained from the Institutional Review Board of Jimma University Institute of Health (Ref No. IHRPGD/672/2019). Mothers who agreed to participate with their respective children gave written informed consent. Confidentiality was maintained by omitting identifiers from study tool and privacy was ensured during the interview. Participants were informed that involvement in this study has no financial and political benefit. All participants were given an information sheet and were only included in the study after providing written informed consent. The study was conducted in accordance with the Declaration of Helsinki.

Provenance and peer review Not commissioned; externally peer reviewed.

Data availability statement All data relevant to the study are included in the article or uploaded as supplementary information. The datasets used and analysed during the current study are included in the manuscript.

Open access This is an open access article distributed in accordance with the Creative Commons Attribution Non Commercial (CC BY-NC 4.0) license, which permits others to distribute, remix, adapt, build upon this work non-commercially, and license their derivative works on different terms, provided the original work is properly cited, appropriate credit is given, any changes made indicated, and the use is non-commercial. See: http://creativecommons.org/licenses/by-nc/4.0/.

ORCID iD

Arefayne Alenko http://orcid.org/0000-0003-4508-0254

\section{REFERENCES}

1 Association AP. Diagnostic and statistical manual of mental disorders (DSM-5®): American psychiatric PUB, 2013.

2 Rey J. IACAPAP textbook of child and adolescent mental health: 2015 edition: international association for child and adolescent psychiatry and allied professions, 2015.

3 Bagner DM, Rodríguez GM, Blake CA, et al. Assessment of behavioral and emotional problems in infancy: a systematic review. Clin Child Fam Psychol Rev 2012;15:113-28.
4 Klein AM, Otto Y, Fuchs S, et al. A prospective study of behavioral and emotional symptoms in preschoolers. Eur Child Adolesc Psychiatry 2015;24:291-9.

5 CDC. Improving Children's Behavioral Health: The Centers for Disease Control and Prevention (CDC), 2019: 15.

6 Danielson ML, Bitsko RH, Ghandour RM, et al. Prevalence of Parent-Reported ADHD diagnosis and associated treatment among U.S. children and adolescents, 2016. J Clin Child Adolesc Psychol 2018;47:199-212.

7 Ghandour RM, Sherman LJ, Vladutiu CJ, et al. Prevalence and treatment of depression, anxiety, and conduct problems in US children. J Pediatr 2019;206:e3:256-67.

8 Lesinskiene S, Girdzijauskiene S, Gintiliene G, et al. Epidemiological study of child and adolescent psychiatric disorders in Lithuania. BMC Public Health 2018;18:548.

9 Chaulagain A, Kunwar A, Watts S, et al. Child and adolescent mental health problems in Nepal: a scoping review. Int J Ment Health Syst 2019;13:53

10 Akpan MU, Ojinnaka NC, Ekanem E. Behavioural problems among schoolchildren in Nigeria. S Afr J Psychol 2010;16:6.

11 Magai DN, Malik JA, Koot HM. Emotional and behavioral problems in children and adolescents in central Kenya. Child Psychiatry Hum Dev 2018:49:659-71.

12 Cortina MAet al. Prevalence of child mental health problems in subSaharan Africa. Arch Pediatr Adolesc Med 2012;166:276-81.

13 Mulatu MS. Prevalence and risk factors of psychopathology in Ethiopian children. J Am Acad Child Adolesc Psychiatry 1995;34:100-9.

14 Beck CT. Maternal depression and child behaviour problems: a meta-analysis. J Adv Nurs 1999;29:623-9.

15 Pratt M, Goldstein A, Levy J, et al. Maternal Depression Across the First Years of Life Impacts the Neural Basis of Empathy in Preadolescence. J Am Acad Child Adolesc Psychiatry 2017;56:e3:20-9.

16 Crews SD, Bender H, Cook CR, et al. Risk and protective factors of emotional and/or behavioral disorders in children and adolescents: a mega-analytic synthesis. Behav Disord 2007:32:64-77.

17 Fergusson DM, Lynskey MT. The effects of maternal depression on child conduct disorder and attention deficit behaviours. Soc Psychiatry Psychiatr Epidemiol 1993;28:116-23.

18 Bajunirwe F, Maling S, Adami H-O, et al. Burden of depressive symptoms and non-alcohol substance abuse; and their association with alcohol use and partner violence: a crosssectional study in four sub-Saharan Africa countries. Glob Ment Health 2018;5:e31.

19 Goodman R. The strengths and difficulties questionnaire: a research note. J Child Psychol Psychiatry 1997;38:581-6.

20 Kalembo FW, Kendall GE, Ali M, et al. Prevalence and factors associated with emotional and behavioural difficulties among children living with HIV in Malawi: a cross-sectional study. BMC Psychiatry 2019;19:60.

21 Kroenke K, Spitzer RL. The PHQ-9: a new depression diagnostic and severity measure. Psychiatr Ann 2002;32:509-15.

22 Kroenke K, Spitzer RL, Williams JB. The PHQ-9: validity of a brief depression severity measure. J Gen Intern Med 2001;16:606-13.

23 Woldetensay YK, Belachew T, Tesfaye M, et al. Validation of the patient health questionnaire (PHQ-9) as a screening tool for depression in pregnant women: Afaan Oromo version. PLoS One 2018:13:e0191782.

24 Sherin KM, Sinacore JM LX-Q, et al. Hits: a short domestic violence screening tool for use in a family practice setting. Fam Med 1998;30:508-12.

25 Iverson KM, King MW, Resick PA, et al. Clinical utility of an intimate partner violence screening tool for female vha patients. J Gen Intern Med 2013;28:1288-93.

26 McLearn KT, Minkovitz CS, Strobino DM, et al. The timing of maternal depressive symptoms and mothers' parenting practices with young children: implications for pediatric practice. Pediatrics 2006;118:e174-82

27 Black MM, Baqui AH, Zaman K, et al. Maternal depressive symptoms and infant growth in rural Bangladesh. Am J Clin Nutr 2009:89:951S-7.

28 Herba CM, Glover V, Ramchandani PG, et al. Maternal depression and mental health in early childhood: an examination of underlying mechanisms in low-income and middle-income countries. Lancet Psychiatry 2016;3:983-92.

29 Carter AS, Garrity-Rokous FE, Chazan-Cohen R, et al. Maternal depression and comorbidity: predicting early parenting, attachment 
security, and toddler social-emotional problems and competencies. $J$ Am Acad Child Adolesc Psychiatry 2001;40:18-26.

30 Reeves RV, Krause E. The effects of maternal depression on early childhood development and implications for economic mobility. Washington, DC: The Brookings Institution, 2019.

31 Islam MR, Islam MR, Ahmed I, et al. Elevated serum levels of malondialdehyde and cortisol are associated with major depressive disorder: a case-control study. SAGE Open Med 2018;6:205031211877395.
32 Davis JAG, Alto ME, Oshri A, et al. The effect of maternal depression on mental representations and child negative affect. $J$ Affect Disord 2020;261:9-20.

33 Noble KG, Houston SM, Brito NH, et al. Family income, parental education and brain structure in children and adolescents. Nat Neurosci 2015;18:773-8.

34 Grinde B, Tambs K. Effect of household size on mental problems in children: results from the Norwegian mother and child cohort study. BMC Psychol 2016;4:31.

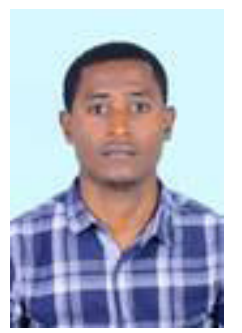

Arefayne Alenko graduated with BSC in clinical nursing from Hawassa University, Ethiopia in July 2013 and MSC in Integrated clinical and community mental health from Jimma University, Ethiopia in November 2017. Since December 2017, he had been serving in a position of academic lecturer in Jimma University department of psychiatry and clinician in psychiatric clinic of Jimma Medical Center. His main research interest includes child and adolescent psychiatry. 